\title{
Identification of rhodamine 123-positive stem cell subpopulations in canine hepatocellular carcinoma cells
}

\author{
HARUMICHI ITOH $^{1}$, SHIMPEI NISHIKAWA ${ }^{1}$, TOMOYA HARAGUCHI ${ }^{1}$, YU ARIKAWA ${ }^{1}$, \\ MASATO HIYAMA ${ }^{2}$, TOSHIE ISERI ${ }^{3}$, YOSHIKI ITOH ${ }^{3}$, MUNEKAZU NAKAICHI ${ }^{3}$, \\ YASUHO TAURA $^{2}$, KENJI TANI ${ }^{2}$ and KAZUHITO ITAMOTO ${ }^{1}$ \\ Departments of ${ }^{1}$ Small Animal Clinical Science, ${ }^{2}$ Veterinary Surgery and ${ }^{3}$ Veterinary Radiology, \\ Joint Faculty of Veterinary Medicine, Yamaguchi University, Yamaguchi City, Yamaguchi 753-8511, Japan
}

Received April 5, 2017; Accepted May 17, 2017

DOI: $10.3892 / b r .2017 .925$

\begin{abstract}
The majority of cases of chemotherapy for hepatocellular carcinoma (HCC) are not effective in human or veterinary medicine due to resistance against anticancer agents. In human medicine, hepatocellular carcinoma stem cells (HCSCs) were recently identified as cytokeratin 19 (CK19)-, cluster of differentiation (CD)-44-, and CD133-positive. However, there are few previous reports regarding canine HCSC (cHCSC). Additionally, to the best of our knowledge, the chemoresistance against anticancer agents of these cHCSCs has not been investigated. In the present study staining of cHCSCs was performed with rhodamine 123, a low-toxicity fluorescent dye for mitochondria, by flow cytometry. There were two subpopulations in the HCC cell line defined by their higher $\left(\mathrm{Rho}^{\mathrm{Hi}}\right)$ and lower $\left(\mathrm{Rho}^{\mathrm{Lo}}\right)$ fluorescence intensity of rhodamine 123 . The $\mathrm{Rho}^{\mathrm{Hi}}$ subpopulation demonstrated a higher Nanog gene expression, sphere-forming ability, and chemoresistance against gemcitabine. However, there was no significant difference between $\mathrm{Rho}^{\mathrm{Hi}}$ and $\mathrm{Rho}^{\mathrm{Lo}}$ regarding the proliferation rate and chemoresistance against mitoxantrone and doxorubicin. The present results indicate that the expression of rhodamine 123 identifies different stem cell subpopulations in a canine HCC cell line.
\end{abstract}

\section{Introduction}

Canine hepatocellular carcinoma (cHCC) accounts for $50 \%$ of primary liver tumors (1). $\mathrm{cHCC}$ is classified clinically as massive, nodular, or diffuse; with $\sim 60 \%$ of $\mathrm{cHCC}$ patients

Correspondence to: Professor Shimpei Nishikawa, Department of Small Animal Clinical Science, Joint Faculty of Veterinary Medicine, Yamaguchi University, 1677-1 Yoshida, Yamaguchi City, Yamaguchi 753-8511, Japan

E-mail: sn2007@yamaguchi-u.ac.jp

Key words: canine hepatocellular carcinoma, cancer stem cell, rhodamine 123 , subpopulation categorized as massive, $30 \%$ as nodular and $10 \%$ as diffuse (2). In addition, nodular and diffuse cHCC exhibit a higher metastatic rate than massive tumors. As a result of the low metastatic rate, patients with massive $\mathrm{cHCC}$ demonstrate a good prognosis when treated surgically. However, nodular and diffuse cHCC have a worse prognosis compared with massive $\mathrm{cHCC}$ (3). For unresectable massive $\mathrm{cHCC}$, and for a part of nodular and diffuse $\mathrm{cHCC}$ cases, transcatheter arterial embolization or transcatheter arterial chemoembolization have been employed experimentally as minimally invasive treatments, and partial therapeutic effects have been reported (4). However, no curative surgical treatment has been established for nodular and diffuse $\mathrm{cHCC}$ to date.

Chemotherapy has generally been considered to have a limited therapeutic effect in primary liver tumors. The presence of P-glycoprotein in the tumors is suggested as a part of therapy resistance mechanism (5). A previous study reported that chemotherapy using mitoxantrone (MTX) resulted in a partial response in a dog with $\mathrm{cHCC}$ (6). Although a response has been reported in a dog following the empirical use of gemcitabine (GEM) (7), a retrospective study of $18 \mathrm{cHCC}$ dogs with GEM (4 massive, 10 nodular and 4 diffuse) concluded that the effect of the therapy was worse than surgical treatment and that the single use of GEM did not improve the survival rate in dogs with $\mathrm{cHCC}$ (8). Considering these issues, effective chemotherapy for $\mathrm{cHCC}$ has not yet been established.

A previous study indicated that cancer tissue is not comprised of a single type of cells, but that cancer stem cells (CSCs) maintain tumor function and morphology (9). CSCs are defined by their ability to self-renew and to generate the heterogeneous lineages of cancer cells that comprise the tumor (10). Therefore, a novel therapeutic strategy targeted at CSCs has recently been investigated. Similarly, a side population of hepatocellular carcinoma stem cells (HCSCs) has been reported (11) to be marked by cluster of differentiation (CD) 133-positive (12,13), CD90-positive (14), and CD44-positive (15) cells. However, there are a small number of reports for canine HCSCs (cHCSCs), such as CD90- and CD44-positive (16,17).

Rhodamine 123 is a low-toxic fluorescent dye for staining mitochondria and is used to determine mitochondrial activity by flow cytometry (18). In human medicine, rhodamine 123 
is considered one of the markers that identify hematopoietic stem cells (HPCs) (19) and renal carcinoma stem cells (20). However, to the best of our knowledge, no previous studies have reported that rhodamine 123 characterizes cHCSCs.

The aim of the current study was to determine cHCSCs in a cHCC cell line using rhodamine 123 and flow cytometry. Additionally, the various biological characteristics and chemoresistance were compared between subpopulations of stem cells with higher $\left(\mathrm{Rho}^{\mathrm{Hi}}\right)$ and lower $\left(\mathrm{Rho}^{\mathrm{Lo}}\right)$ rhodamine expression.

\section{Materials and methods}

Cell line and culture. The CHCC cell line (AZACH) was purchased from Cosmo Bio Co., Ltd., (Tokyo, Japan) and maintained in Eagle's minimum essential medium (EMEM; Wako Pure Chemical Industries, Ltd., Osaka, Japan) supplemented with Sigma-Aldrich 5\% fetal bovine serum (FBS; Merck KGaA, Darmstadt, Germany), amino acid supplement (GlutaMAX; Thermo Fisher Scientific, Inc., Waltham, MA, USA), and antibiotic-antimycotic agents (PSM; $100 \mathrm{U} / \mathrm{ml}$ penicillin, $100 \mu \mathrm{g} / \mathrm{ml}$ streptomycin and $0.25 \mu \mathrm{g} / \mathrm{ml}$ amphotericin $\mathrm{B}$, final concentrations, all from Nacalai Tesque, Inc., Kyoto, Japan). They were subsequently cultured for two days at $37^{\circ} \mathrm{C}$ in an atmosphere containing $5 \% \mathrm{CO}_{2}$.

Flow cytometry and cell sorting. The cells were enzymatically dissociated using Accutase solution (Innovative Cell Technologies, Inc., San Diego, CA, USA) after washing with phosphate-buffered saline (PBS). The cells were resuspended with Dulbecco's PBS supplemented with $1 \%$ FBS and $1 \mathrm{mM}$ EDTA·3Na (Wako Pure Chemical Industries, Ltd.). Cells were stained with a viability probe (Zombie NIR; BioLegend, Inc., San Diego, CA, USA) to stain the dead cells. In addition, wells were incubated with $0.1 \mu \mathrm{g} / \mathrm{ml}$ rhodamine 123 (Dojindo Molecular Technologies, Inc., Kumamoto, Japan) at $37^{\circ} \mathrm{C}$ for $30 \mathrm{~min}$ and washed twice with PBS. Subsequent to washing, the labeled cells were analyzed using flow cytometry (Accuri C6; BD Biosciences, Franklin Lakes, NJ, USA) and sorting was performed using a cell sorter (SH800; Sony Biotechnology, Inc., Tokyo, Japan). A negative control was run using DPBS without rhodamine 123. Data were analyzed using FlowJo software (version 10.1; Tree Star, Inc., Ashland, OR, USA).

Reverse transcription-quantitative polymerase chain reaction $(R T-q P C R)$. Total RNA was extracted from the Rho ${ }^{\mathrm{Hi}}$ and $\mathrm{Rho}^{\mathrm{Lo}}$ subpopulations incubated for $24 \mathrm{~h}$ after sorting using a commercially available kit (miRNeasy Mini kit; Qiagen, Tokyo, Japan). RT to single-strand cDNA was performed using a commercially available kit (ReverTra Ace qPCR RT Master Mix with gDNA Remover; Toyobo Co., Ltd., Osaka Japan) according to the manufacturer's instructions. For qPCR, the Nanog primers (forward, TGGAACAATCCGCTCCACAA and reverse, GATGGACTCCAGATCACCCATAGAA) and templates were mixed with the SYBR Premix Ex TaqII (Takara Bio, Inc., Otsu, Japan). DNA was amplified by 45 cycles of denaturation for $5 \mathrm{sec}$ at $95^{\circ} \mathrm{C}$ and annealing for $30 \mathrm{sec}$ at $60^{\circ} \mathrm{C}$ using the Thermal Cycler Dice Real-Time
System II (Takara Bio, Inc.). Data generated from each PCR reaction were analyzed using the Thermal Cycler Dice Real-Time System version 2.10B (Takara Bio, Inc.). The relative quantity of mRNA was normalized to that of hypoxanthine phosphoribosyltransferase 1 (forward, GGAGCATAATCC AAAGATGGTCAA and reverse, TCAGGTTTATAGCCA ACACTTCGAG). The data analysis was performed using the $2^{-\Delta \Delta \mathrm{Cq}}$ method (21).

Cell proliferation assay. Cell proliferation was analyzed using WST-8 and a Cell Counting Kit-8 (CCK-8; Dojindo Molecular Technologies, Inc.) according to the manufacturer's instructions. Briefly, sorted $\mathrm{Rho}^{\mathrm{Hi}}$ and $\mathrm{Rho}^{\mathrm{Lo}}$ subpopulations were seeded into 96 -well plates at $3 \times 10^{3}$ cells/well. Subsequently, $100 \mu \mathrm{l}$ fresh medium containing $10 \mu \mathrm{l} \mathrm{CCK}-8$ solution was added to each well after 12, 24, 48 and $72 \mathrm{~h}$. The absorbance at a wavelength of $450 \mathrm{~nm}$ of each well was measured on an Epoch microplate spectrophotometer (BioTek Instruments, Inc., Winooski, VT, USA) followed by incubation at $37^{\circ} \mathrm{C}$ for $1 \mathrm{~h}$. A total of six replicates were prepared for each group.

Sphere formation assay. Sorted cells were seeded in ultra-low attachment plates (Corning Inc., Corning, NY, USA) at a density of $1 \times 10^{6}$ cells/dish and cultured with EMEM supplemented with 5\% FBS, amino acid supplement (GlutaMAX) and antibiotic-antimycotic agents (PSM; $100 \mathrm{U} / \mathrm{ml}$ penicillin, $100 \mu \mathrm{g} / \mathrm{ml}$ streptomycin and $0.25 \mu \mathrm{g} / \mathrm{ml}$ amphotericin $\mathrm{B}$, final concentrations) for 3 days. Spheres were counted from 6 sites using a fluorescence microscope (BZ-9000; Keyence Corporation, Osaka, Japan) for quantitative analysis of sphere formation.

Chemoresistance assay. The cytotoxic effect in each subpopulation was determined by WST-8 (CCK-8) according to the manufacturer's instructions. Briefly, cells were seeded in 96-well plates at a density of $3 \times 10^{3}$ cells/well with $0.1,0.5,1,5$, 10 and $50 \mu \mathrm{M}$ of doxorubicin (DOX), MTX and GEM (Wako Pure Chemical Industries, Ltd.). Following incubation for $24 \mathrm{~h}$ at $37^{\circ} \mathrm{C}$ in an atmosphere containing $5 \% \mathrm{CO}_{2}, 100 \mu \mathrm{l}$ fresh medium containing $10 \mu \mathrm{l}$ CCK-8 solution was added to each well, followed by incubation at $37^{\circ} \mathrm{C}$ for $1 \mathrm{~h}$. The absorbance at a wavelength of $450 \mathrm{~nm}$ of each well was measured on an Epoch microplate spectrophotometer. A total of six replicates were prepared for each group.

Statistical analysis. Statistical analysis was performed using GraphPad Prism version 6.01 for Windows (GraphPad Software, Inc., La Jolla, CA, USA). The results were expressed as means \pm standard error. Comparisons between two groups were performed using the independent t-test. Multiple comparisons were performed with one-way ANOVA and $\mathrm{P}<0.05$ was considered to indicate a statistically significant difference.

\section{Results}

Rhodamine 123 staining and sorting of $\mathrm{cHCC}$. Flow cytometry of cultured cHCC excluding dead cells confirmed that rhodamine was expressed. Cells labeled by rhodamine 

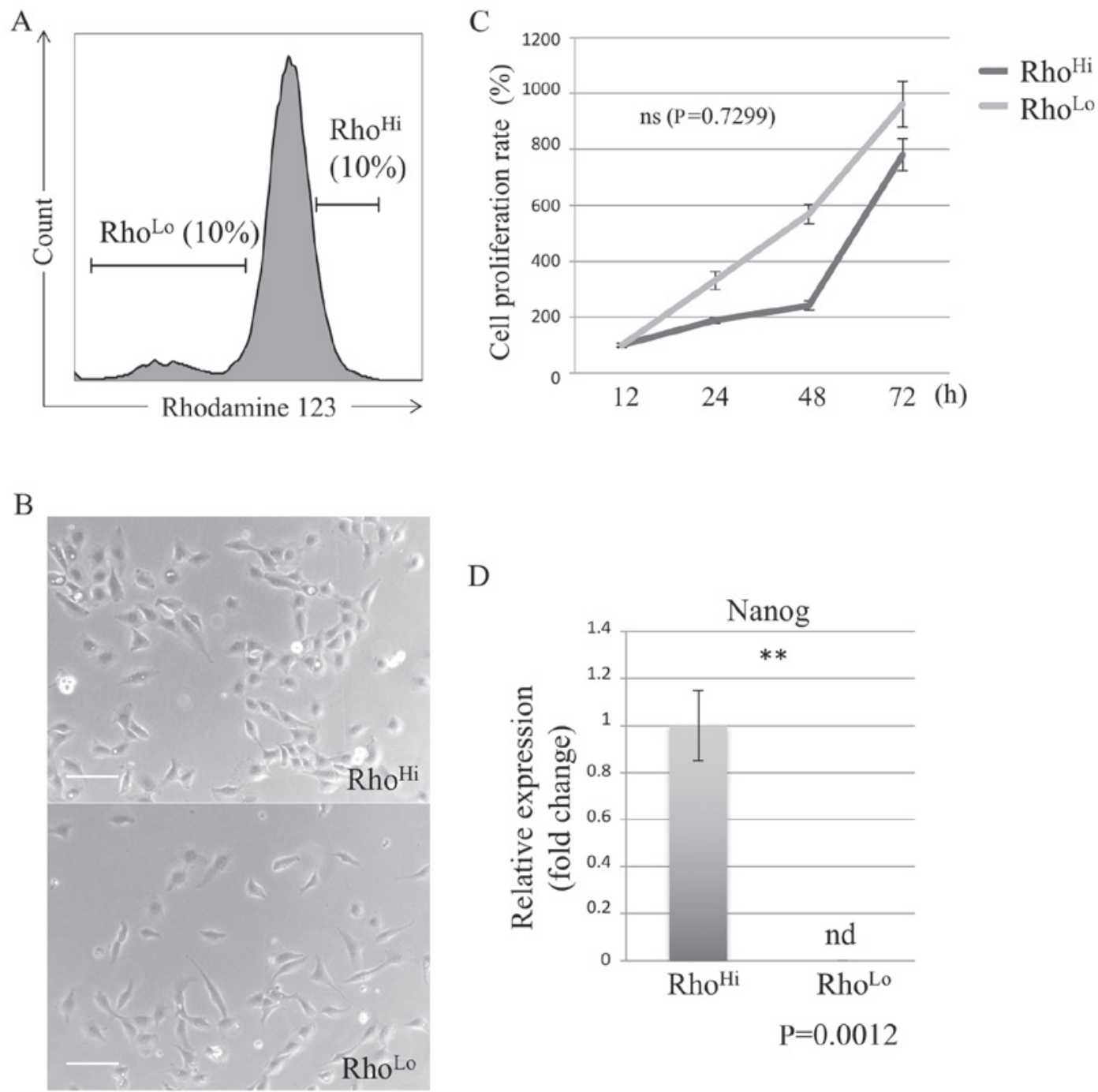

Figure 1. Detection of $\mathrm{Rho}^{\mathrm{Hi}}$ and $\mathrm{Rho}^{\mathrm{Lo}}$ subpopulations of $\mathrm{cHCC}$ and evaluation of proliferation rates and Nanog expression levels. (A) Flow cytometric analysis of cHCC. The difference in the expression $(\sim 10 \%)$ of rhodamine was considered to characterize cells as $\mathrm{Rho}^{\mathrm{Hi}}$ and $\mathrm{Rho}^{\mathrm{Lo}}$. (B) The sorted $\mathrm{Rho}{ }^{\mathrm{Hi}}$ and $\mathrm{Rho} \mathrm{O}^{\mathrm{Lo}}$ cells exhibited similar morphologies following incubation for $24 \mathrm{~h}$ (scale bar, $100 \mu \mathrm{m}$ ). (C) No difference in the cell proliferation rates was identified between the Rho ${ }^{\mathrm{Hi}}$ and $\mathrm{Rho}^{\mathrm{Lo}}$ subpopulations. (D) Rho ${ }^{\mathrm{Hi}}$ exhibited higher Nanog expression levels than Rho ${ }^{\mathrm{Lo}}$. Values are expressed as means \pm standard error $(\mathrm{n}=5)$. ${ }^{* *} \mathrm{P}<0.01 \mathrm{Rho}^{\mathrm{Hi}}$ vs. Rho ${ }^{\mathrm{Lo}}$. Ns, not significant; nd, not detected; cHCC, canine hepatocellular carcinoma.

were sorted by their expression of rhodamine into $\mathrm{Rho}^{\mathrm{Hi}}$ and $\mathrm{Rho}^{\mathrm{Lo}}$ (Fig. 1A). Subsequent to sorting, the Rho ${ }^{\mathrm{Hi}}$ and $\mathrm{Rho}^{\mathrm{Lo}}$ subpopulations were incubated for $24 \mathrm{~h}$, and the two subpopulations exhibited a similar morphology (Fig. 1B).

Comparison of proliferation rate. To assess the difference in the proliferation potential between the $\mathrm{Rho}^{\mathrm{Hi}}$ and $\mathrm{Rho}^{\mathrm{Lo}}$ subpopulations, the proliferation rate was measured in each subpopulation using the WST assay. As a result, the proliferation potential of the $\mathrm{Rho}^{\mathrm{Hi}}$ and $\mathrm{Rho}^{\mathrm{Lo}}$ subpopulations of $\mathrm{cHCC}$ was not identified to be significantly different (Fig. 1C).

Comparison of Nanog expression. The gene expression of Nanog, a common type of stem cell marker, was evaluated using RT-qPCR. The gene expression level of Nanog in Rho ${ }^{\mathrm{Hi}}$ was identified to be higher than that in Rho ${ }^{\text {Lo }}$ (Fig. 1D).

Comparison of sphere formation. A sphere formation assay was performed using ultra-low attachment dishes and demonstrated the formation of tumor spheres in cultures of $\mathrm{Rho}^{\mathrm{Hi}}$ and $\mathrm{Rho}^{\mathrm{Lo}}$ subpopulations (Fig. 2A). However, the Rho ${ }^{\mathrm{Hi}}$ subpopulation exhibited a significantly higher number of sphere formations per visual field than the Rho ${ }^{\mathrm{Lo}}$ subpopulation (Fig. 2B).

Comparison of chemoresistance ability. Chemoresistance against MTX, GEM, and DOX was determined for the Rho ${ }^{\mathrm{Hi}}$ and $\mathrm{Rho}^{\mathrm{Lo}}$ subpopulations. Rho ${ }^{\mathrm{Hi}}$ exhibited a higher survival rate than Rho ${ }^{\mathrm{Lo}}$ when GEM was administered (Fig. 3B). However, no significant difference in the chemoresistance potential was identified between the $\mathrm{Rho}^{\mathrm{Hi}}$ and $\mathrm{Rho}^{\mathrm{Lo}}$ subpopulations with MTX or DOX administration.

\section{Discussion}

In the current study $\mathrm{Rho}^{\mathrm{Hi}}$ demonstrated higher Nanog expression level and sphere formation ability than $\mathrm{Rho}^{\mathrm{Lo}}$. In addition, $\mathrm{Rho}^{\mathrm{Hi}}$ exhibited greater chemoresistance potential to GEM when compared with $\mathrm{Rho}^{\mathrm{Lo}}$. However, no 
A
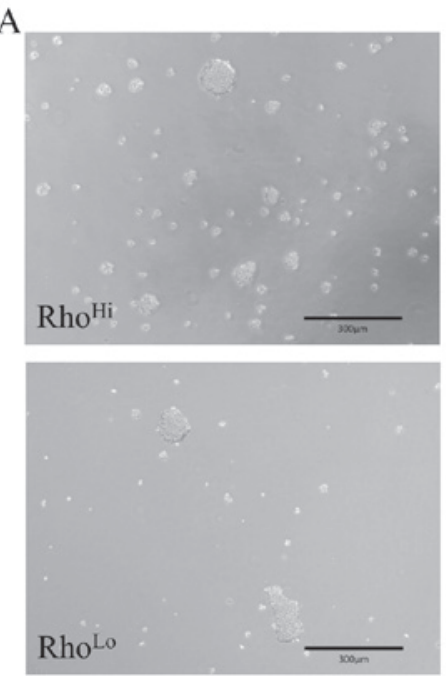

B

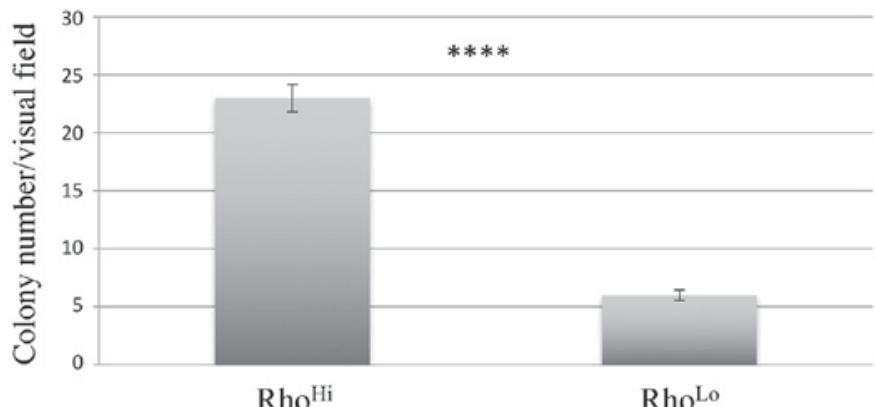

$\mathrm{P}<0.0001$

Figure 2. Sphere formation ability of Rho ${ }^{\mathrm{Hi}}$ and $\mathrm{Rho}^{\mathrm{LO}}$ subpopulations. (A) Three days after cultivation of $\mathrm{Rho}^{\mathrm{Hi}}$ and $\mathrm{Rho} \mathrm{L}^{\mathrm{Lo}}$ subpopulations in ultra-low attachment dishes, the two subpopulations exhibited spherical colonies (scale bar, $300 \mu \mathrm{m}$ ). (B) Quantitative analysis of sphere formation revealed a higher sphere formation ability in the $\mathrm{Rho}^{\mathrm{Hi}}$ subpopulation. ${ }^{* * * *} \mathrm{P}<0.0001$ as indicated between $\mathrm{Rho}{ }^{\mathrm{Hi}}$ and $\mathrm{Rho}^{\mathrm{Lo}}$.

A

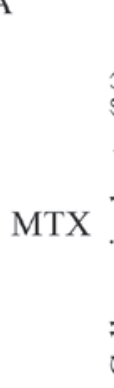

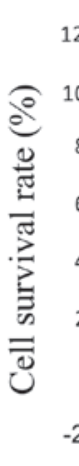

120

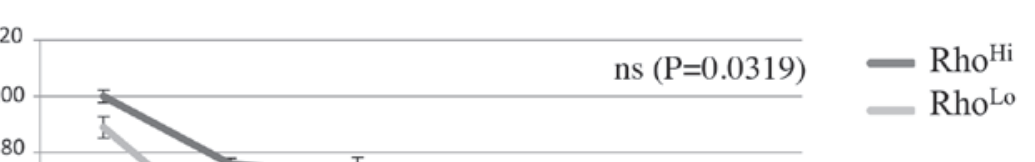

B

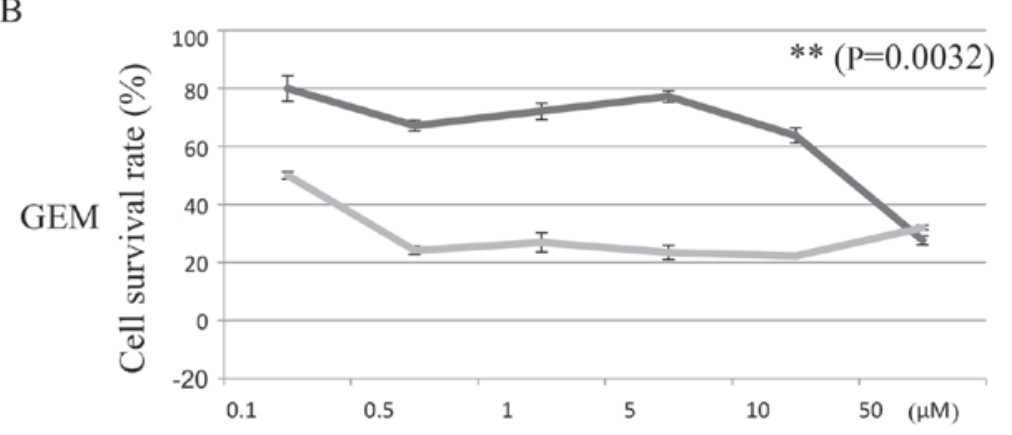

C

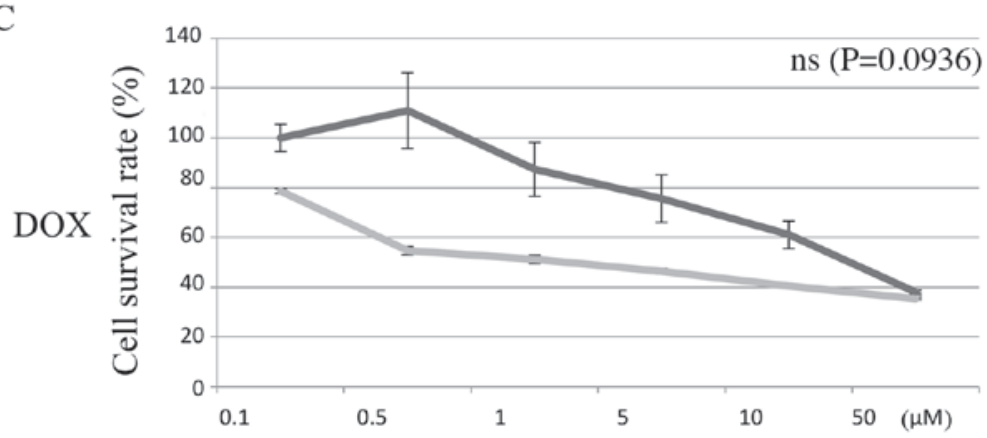

Figure 3. Chemoresistance against MTX, GEM, and DOX was determined for the $\mathrm{Rho}^{\mathrm{Hi}}$ and $\mathrm{Rho}^{\mathrm{Lo}}$ subpopulations. (A) No significant difference regarding the chemoresistance potential was shown between the $\mathrm{Rho}^{\mathrm{Hi}}$ and $\mathrm{Rho}^{\mathrm{Lo}}$ subpopulations with MTX treatment. (B) Rho ${ }^{\mathrm{Hi}}$ exhibited a higher survival rate than Rho ${ }^{\mathrm{Lo}}$ following GEM treatment. (C) No significant difference regarding the chemoresistance potential was identified between the $\mathrm{Rho}^{\mathrm{Hi}}$ and $\mathrm{Rho}^{\mathrm{Lo}}$ subpopulations with DOX treatment. ${ }^{* *} \mathrm{P}<0.01$ as indicated between $\mathrm{Rho}^{\mathrm{Hi}}$ and $\mathrm{Rh} \mathrm{L}^{\mathrm{Lo}}$. Ns, not significant; MTX, mitoxantrone; GEM, gemcitabine; DOX, doxorubicin. 
significant difference between $\mathrm{Rho}^{\mathrm{Hi}}$ and $\mathrm{Rho}^{\mathrm{Lo}}$ regarding the proliferation rate or chemoresistance against MTX and DOX was identified.

Rhodamine 123 is absorbed easily by living cells, becoming concentrated in the mitochondria (22). Mitochondria are categorized as intracellular organelles and functionally supply adenosine triphosphate as a result of cell respiration and metabolism. Previous studies propose that reactive oxygen species produced in mitochondrial respiration are correlated with aging and the formation of malignancies $(23,24)$. Furthermore, recent studies have revealed rhodamine to be a marker of stem cells. However, identifying which stem cells display either higher or lower expression levels of rhodamine is complicated. Regarding adult stem cells, a few reports have identified HPC as having a low expression of rhodamine $123(19,25)$. Conversely, in cancer cells, a previous study revealed that subpopulations with a higher expression of rhodamine exhibited higher proliferation, sphere formation, radio-resistance and tumor differentiation potential than those with a lower expression of rhodamine (26).

To the best of our knowledge, there is only one report regarding HCSCs identified by rhodamine expression in humans (27). In the present study, primary HCCs were obtained from clinical patients; primary HCC were compared with cells cultured with DOX and 5-fluorouracil, which were regarded as HCSCs. HCSCs exhibited more stem cell markers, sphere formation, and tumor differentiation and a lower level of rhodamine expression than primary cells (27). The present study demonstrated that the expression of rhodamine was a poor stem cell marker; however, it did not examine chemoresistance or sphere-forming ability in the $\mathrm{Rho}^{\mathrm{Hi}}$ and $\mathrm{Rho}^{\mathrm{Lo}}$ subpopulations (24). Additionally, cells from the clinical patients cultured with DOX and 5-fluorouracil were regarded as HCSCs. Thus, these were cells selected for their chemoresistance and ability to proliferate well in dishes (24). As a result, $\mathrm{Rho}^{\mathrm{Lo}}$ cells may have been exhibited as being poorly differentiated.

Treatment for $\mathrm{cHCC}$ is limited, and poor prognoses have been reported for $\mathrm{cHCC}$ with metastasis or diffusion through an entire hepatic lobe, although massive cHCC has a good prognosis when it is treated surgically. Thus, more effective treatments are required for nodular and diffuse $\mathrm{cHCC}$. A recent study in human medicine have proposed a novel strategy for the treatment of cancer targeted at CSCs, and notable results have been presented regarding CSCs from basic and clinical trials (28). Veterinary medicine follows human medicine, and CSCs have been reported from various types of solid tumor and hematological malignancies (29-32). To the best of our knowledge, the current study is the first to describe CSCs identified by rhodamine in a canine cancer cell line, and it may lead to basic studies regarding cHCSC-targeting treatment. Further studies are required to reveal the mechanism by which mitochondrial activity affects the stem cell characteristics and chemoresistance of $\mathrm{cHCC}$.

\section{Acknowledgements}

The present study was partly supported by the Japan Society for the Promotion of Science KAKENHI (grant no. 26893172).

\section{References}

1. Withrow SJ, Vail DM and Page RL: Withrow and MacEwen's small animal clinical oncology. 5th edition. Elsevier, St. Louis, MI, 2013.

2. Patnaik AK, Hurvitz AI, Lieberman PH and Johnson GF: Canine hepatocellular carcinoma. Vet Pathol 18: 427-438, 1981.

3. Liptak JM, Dernell WS, Monnet E, Powers BE, Bachand AM, Kenney JG and Withrow SJ: Massive hepatocellular carcinoma in dogs: 48 cases (1992-2002). J Am Vet Med Assoc 225: 1225-1230, 2004.

4. Weisse C, Clifford CA, Holt D and Solomon JA: Percutaneous arterial embolization and chemoembolization for treatment of benign and malignant tumors in three dogs and a goat. J Am Vet Med Assoc 221: 1430-1436, 1419, 2002.

5. Ginn PE: Immunohistochemical detection of P-glycoprotein in formalin-fixed and paraffin-embedded normal and neoplastic canine tissues. Vet Pathol 33: 533-541, 1996.

6. Ogilvie GK, Obradovich JE, Elmslie RE, Vail DM, Moore AS, Straw RC, Dickinson K, Cooper MF and Withrow SJ: Efficacy of mitoxantrone against various neoplasms in dogs. J Am Vet Med Assoc 198: 1618-1621, 1991

7. Moore AS and Kitchell BE: New chemotherapy agents in veterinary medicine. Vet Clin North Am Small Anim Pract 33: 629-649, 2003.

8. Elpiner AK, Brodsky EM, Hazzah TN and Post GS: Single-agent gemcitabine chemotherapy in dogs with hepatocellular carcinomas. Vet Comp Oncol 9: 260-268, 2011.

9. Visvader JE and Lindeman GJ: Cancer stem cells in solid tumours: Accumulating evidence and unresolved questions. Nat Rev Cancer 8: 755-768, 2008.

10. Clarke MF, Dick JE, Dirks PB, Eaves CJ, Jamieson $\mathrm{CH}$, Jones DL, Visvader J, Weissman IL and Wahl GM: Cancer stem cells - perspectives on current status and future directions: AACR Workshop on cancer stem cells. Cancer Res 66: 9339-9344, 2006.

11. Haraguchi N, Utsunomiya T, Inoue H, Tanaka F, Mimori K, Barnard GF and Mori M: Characterization of a side population of cancer cells from human gastrointestinal system. Stem Cells 24: 506-513, 2006

12. Suetsugu A, Nagaki M, Aoki H, Motohashi T, Kunisada T and Moriwaki H: Characterization of $\mathrm{CD}_{133^{+}}$hepatocellular carcinoma cells as cancer stem/progenitor cells. Biochem Biophys Res Commun 351: 820-824, 2006.

13. Ma S, Lee TK, Zheng BJ, Chan KW and Guan XY: CD133+ $\mathrm{HCC}$ cancer stem cells confer chemoresistance by preferential expression of the Akt/PKB survival pathway. Oncogene 27: 1749-1758, 2008

14. Yang ZF, Ho DW, Ng MN, Lau CK, Yu WC, Ngai P, Chu PW, Lam CT, Poon RT and Fan ST: Significance of CD90 ${ }^{+}$cancer stem cells in human liver cancer. Cancer Cell 13: 153-166, 2008.

15. Endo K and Terada T: Protein expression of CD44 (standard and variant isoforms) in hepatocellular carcinoma: Relationships with tumor grade, clinicopathologic parameters, p53 expression, and patient survival. J Hepatol 32: 78-84, 2000.

16. Michishita M, Ezaki S, Ogihara K, Naya Y, Azakami D, Nakagawa T, Sasaki N, Arai T, Shida T and Takahashi K: Identification of tumor-initiating cells in a canine hepatocellular carcinoma cell line. Res Vet Sci 96: 315-322, 2014

17. Cogliati B,Aloia TP, Bosch RV, Alves VA,Hernandez-Blazquez FJ and Dagli ML: Identification of hepatic stem/progenitor cells in canine hepatocellular and cholangiocellular carcinoma. Vet Comp Oncol 8: 112-121, 2010.

18. Ronot X, Benel L, Adolphe M and Mounolou JC: Mitochondrial analysis in living cells: The use of rhodamine 123 and flow cytometry. Biol Cell 57: 1-7, 1986.

19. McKenzie JL, Takenaka K, Gan OI, Doedens M and Dick JE: Low rhodamine 123 retention identifies long-term human hematopoietic stem cells within the Lin ${ }^{-} \mathrm{CD} 34^{+} \mathrm{CD} 38^{-}$population. Blood 109: 543-545, 2007.

20. Bussolati B, Bruno S, Grange C, Ferrando U and Camussi G: Identification of a tumor-initiating stem cell population in human renal carcinomas. FASEB J 22: 3696-3705, 2008.

21. Livak KJ and Schmittgen TD: Analysis of relative gene expression data using real-time quantitative PCR and the $2^{-\Delta \Delta C q}$ method. Methods 25: 402-408, 2001.

22. Johnson LV, Walsh ML and Chen LB: Localization of mitochondria in living cells with rhodamine 123. Proc Natl Acad Sci USA 77: 990-994, 1980.

23. Harman D: Aging: A theory based on free radical and radiation chemistry. J Gerontol 11: 298-300, 1956. 
24. Gatenby RA and Gillies RJ: Why do cancers have high aerobic glycolysis? Nat Rev Cancer 4: 891-899, 2004.

25. Wagner-Souza K, Diamond HR, Ornellas MH, Gomes BE, Almeida-Oliveira A, Abdelhay E, Bouzas LF and Rumjanek VM: Rhodamine 123 efflux in human subpopulations of hematopoietic stem cells: Comparison between bone marrow, umbilical cord blood and mobilized peripheral blood CD $34^{+}$cells. Int J Mol Med 22: 237-242, 2008

26. Lu J, Cui Y, Zhu J, He J, Zhou G and Yue Z: Biological characteristics of Rh123 (high) stem-like cells in a side population of 786-O renal carcinoma cells. Oncol Lett 5: 1903-1908, 2013.

27. Vu NB, Nguyen TT, Tran LC, Do CD, Nguyen BH, Phan NK and Pham PV: Doxorubicin and 5-fluorouracil resistant hepatic cancer cells demonstrate stem-like properties. Cytotechnology 65: 491-503, 2013.

28. $\mathrm{Xu} \mathrm{LB}$ and Liu C: Role of liver stem cells in hepatocarcinogenesis. World J Stem Cells 6: 579-590, 2014.
29. Wilson H, Huelsmeyer M, Chun R, Young KM, Friedrichs K and Argyle DJ: Isolation and characterisation of cancer stem cells from canine osteosarcoma. Vet J 175: 69-75, 2008

30. Penzo C, Ross M, Muirhead R, Else R and Argyle DJ: Effect of recombinant feline interferon-omega alone and in combination with chemotherapeutic agents on putative tumour-initiating cells and daughter cells derived from canine and feline mammary tumours. Vet Comp Oncol 7: 222-229, 2009.

31. Stoica G, Lungu G, Martini-Stoica H, Waghela S, Levine J and Smith R III: Identification of cancer stem cells in dog glioblastoma. Vet Pathol 46: 391-406, 2009.

32. Liu W, Selçuk F, Rütgen BC, Moulay M, Willenbrock S, HammerSE,Sterenczak KA,Junghanss C,Hewicker-TrautweinM, Nolte I, et al: Evaluation of stem cell marker expression in canine B-cell lymphoma cell lines, B-cell lymphoma-generated spheres and primary samples. Anticancer Res 35: 2805-2816, 2015. 